\title{
An Economic Analysis of the Reservation Policy in India
}

\author{
Sampurna Basu
}

Persistent socio-religious stratification in India has resulted in widespread inequity in all spheres of life, particularly for those born in the lower ranks of the social caste order. The effects of these inequities are visible amongst the lower caste in the form of poverty, low standards of living, unemployment, and lack of education. To counter this, India's government introduced a reservation policy as a form of affirmative action that reserves a percentage of legislative seats for the Scheduled Castes, Scheduled Tribes, and Other Backward Castes in the spheres of education, employment, and politics. This paper looks into the usefulness of this policy in making better opportunities available for the Scheduled Castes and Scheduled Tribes and examines its effectiveness using economic analysis. In doing so, the paper explores certain problems, such as ambiguous data, child labor, and rent-seeking behavior, and recommends setting up better screening methods to rectify these issues in an effort to ensure equitable distribution of welfare benefits amongst the recipients of the reservation policy.

https://doi.org/10.4079/pp.v28i0.2 
SAMPURNA BASU is a second-year M.P.P candidate with a concentration in social policy. She graduated from St. Xavier's College, Kolkata, India with an honors degree in Sociology. She is currently interning with the Justice Love Foundation and works in the field of social justice and impact investing. When not studying, she enjoys going for long walks and binge-watching shows on Netflix.

\section{ACKNOWLEDGEMENTS}

The author would first like to thank her parents for their support of her education and interests. She would also like to thank Professor Leah Brooks for her thoughtful insights and guidance throughout this experience. The author appreciates her editing team, her Associate Editor, Shabir Eman for his careful editing, tireless efforts and critical contributions to this paper, as well as Sydney Hamilton, Editor-in-Chief of Policy Perspectives, for her helpful feedback and invaluable edits. Finally, she would like to thank her friends who provided her with immense support and indispensable suggestions throughout this process. 


\section{INTRODUCTION}

A significant characteristic of the Indian culture is its hierarchical caste system. Caste in India is a Hindu socio-religious institutional sanction. Within Hinduism, one is born into a caste group. There are four predominant caste groups in India: Brahmins, Kshatriyas, Vaishyas, and Shudras. They are listed here in their respective vertical hierarchical order, with the higher born being more privileged in terms of social status, education, and wealth. Those born as Shudras, or the lower castes, have historically suffered at the hands of the privileged upper castes and are now considered Scheduled Castes (SC) owing to their lower socio-economic status in society. As outlined below, the SCs have special privileges to avoid socio-religious discrimination. Another social group with significant representation in the Indian population are the Scheduled Tribes (ST). Scheduled Tribes have traditionally existed in isolated, remote pockets of the country and have been left out of mainstream society and its privileges (Appendix Table 1).

While SCs are groups identified with low social and ritual standing in the Hindu caste hierarchy, STs are groups identified by their indigenous culture, dialect, geographic isolation, livelihood, and linguistic characteristics. The SCs make up 20 percent of the Indian population, while the STs (also referred to as India's indigenous population) make up 9 percent of India's population. Both the SC and the ST groups experience discrimination from the Indian system; while the SC population has been unable to access the benefits of socioeconomic growth that India has experienced over the past decades due to social discrimination based on the caste hierarchy system, the ST population has not become a part of mainstream Indian society due to their remote location, while also periodically being subject to discrimination due to the Hindu caste system (Statista 2020; Kaletski and Prakash 2016).

Social stratification, or the allocation of individuals into different hierarchies based on power, status or prestige (Anderson 2011), has led to widespread poverty amongst these social groups and pushed most people in these groups under the poverty line. A study conducted in 2004 and 2005 found that approximately 36.8 percent of the SC population residing in the rural regions live under the poverty line, while 16.1 percent of the general caste population live under the poverty line. In urban spaces, 39.9 percent of the SC population live under the poverty line. In comparison, 25.7 percent of the general caste population live under the poverty line (Ministry of Social Justice and Empowerment 2021). This goes to show that a majority population from these social groups continue to live in poverty and this further leads to a lack of basic amenities, food, proper shelter, quality education, and widespread unemployment.

To promote social mobility and reverse the inequities that result from hierarchical discrimination, the Indian government launched a reservation system for the SCs, STs, and other underprivileged castes in 2006 through the $93^{\text {rd }}$ Amendment Act of the Constitution. The reservation system as defined in Article 15(5) and 16(3) of the constitution is a type of affirmative action policy that reserves a percentage of seats exclusively for lower caste members in educational and public service institutions. The program provides select SCs and STs with better opportunities to participate in every sphere of the social and political system. This policy's characterizing factor is that it is primarily based on caste identity rather than on any other socio-economic factors. There is currently around 15 percent reservation for SCs and 7.5 percent reservation for STs in education 
and public employment (George 2020) with most institutions reserving a certain number of seats exclusively for students from these groups.

Empirical research suggests that this program has successfully introduced reforms and ensures that these castes have some representation in politics, governmental positions, education, and the labor market. However, this paper discusses certain limitations preventing the program from reaching a wider target group. This paper will use an economic approach to explore the variety of factors that inform the policy as it strives to uplift the marginalized status of SCs and STs in society. This paper will also discuss certain concepts from behavioral economics that help analyze future policymaking and delivery of this policy from the government leaders to the masses.

\section{OVERVIEW}

Historically, those born into lower castes have always belonged to a downtrodden section of society, both economically and socio-politically. While the Scheduled Castes and Scheduled Tribes in India are two of the underprivileged social groups who have achieved some level of social mobility due to India's reservation policy, urbanization has allowed some members of these communities to prosper more than others. Because of the opportunities that come with moving to an urban area, some people with lower caste identities are attaining a level of socio-economic affluency that most belonging to these groups cannot afford. Since this social status change is challenging to monitor, it often leads to flaws in the existing reservation policy, resulting in inequity and misplacement of benefits. Basing a policy on a system that is administratively difficult to monitor is an unreliable criterion to qualify for government support. As essential resources rely on economic abilities, the Indian government's decision to use only social caste as a foundation for the existing reservation policy fails to serve those who require aid the most.

\section{THE POLITICAL SPHERE AND LOCAL GOVERNANCE}

In India, the reservation policy guarantees marginalized communities reserved seats in the national and state government legislatures, educational institutions, and certain government jobs (Osborne 2001 as cited in Borooah, Dubey and Iyer 2007). While the Scheduled Tribes take advantage of all of these opportunities, they have gained the most benefits from involvement in politics as it gives them the opportunity to put forth and act upon the economic needs of the community. Chin and Prakash (2011) find that a 1 percent increase in the number of seats reserved in the state legislature for STs reduces rural poverty in the state by 1.2 percent. According to Duflo (2005), a higher number of elected representatives from the ST community helps to reduce poverty through the entire community by introducing reformative policies to uplift those who cannot access welfare benefits (Chin and Prakash 2011, Duflo 2005). Regarding SCs, Duflo finds that a 1 percent rise in the fraction of seats reserved for SCs in the state legislature is associated with a 0.6 percent increase in job quotas (Duflo 2005). The SCs have progressed more in the field of education and in the labor market than poverty alleviation.

Given that reservation for both SC and ST communities is based on their population within a state, these communities have greater representation in local and state governments in states where they are more heavily populated. Since most of the ST community resides in isolated areas, national welfare plans do not adequately consider their needs as they are not targeted enough. 
However, despite living in isolated pockets, securing positions in the local Panchayats (governments) has proved beneficial for ST communities, as they can design welfare plans that best suit the ST community's needs. However, as the ST community's demands for basic needs are met, there is a converse effect on participation in education or the job market. Since geographical isolation prevents investment in public goods, like the water system and roads through national welfare plans, the ST leaders allocate generated funds towards it which significantly reduces investment and involvement in education and schools (Duflo 2005, Chin and Prakash 2011).

Different caste communities have different welfare preferences. Thus, irrespective of the region's social composition, the political representative's caste identity decides fund allocation and investment in different social welfare services (Duflo 2005). A reservation policy based on one's identity may often leave members of many upper caste groups, who are equally poor, lacking in equal opportunities. As a result, the non-ST or non-SC poor or landless population does not benefit from affirmative actions as much as the poor or landless ST and SC community. A phenomenon that plays an important role here is that of "elite capture"-a form of corruption where the socio-economically advantaged tend to gain control over everyone's socio-economic benefits, irrespective of caste barriers (Taiwo 2020). This phenomenon can be seen in India's reservation policy when socio-economically influential members of the ST and SC population use their power and lower caste identity to benefit from the existing welfare plans explicitly meant for the socio-economically underprivileged individuals in a community. In this case, many socioeconomically powerful individuals among the marginalized castes receive benefits at the cost of those non-marginalized people who are socio-economically less powerful (Kaletski and Prakash 2016).

It is important to note that in the urban sphere, the trend is notably different. As both marginalized and non-marginalized caste leaders push for poverty alleviation programs, both communities benefit equally. Nonetheless, the welfare policies pushed forward, particularly by the ST leaders, have helped reduce the intensity of poverty in both rural and urban India among all individuals (Chin and Prakash 2011).

\section{RESERVATION IN THE FIELD OF EDUCATION AND EMPLOYMENT}

In spite of reservation for the marginalized in the government sector, less progress has been made regarding education and employment. A wide range of literature shows a bias in employment opportunities toward upper caste Hindus still exists, who benefit from higher employment rates than lower caste communities. Social discrimination continues to act as a barrier for lower caste communities to obtain quality education in India. Research conducted by Borooah, Dubey, and Iyer (2007) shows that, of their sample, 92 percent of casual wage laborers attained education below the secondary level, and of that 92 percent, 47 percent belong to the SC caste population. Further, 49 percent of casual wage laborers are illiterate. However, with the SC and ST communities' gradual social mainstreaming over the past decades, the probability of finding casual labor has risen by 0.10 points and 0.184 points, respectively. Sixty-one percent of salaried workers have at least a secondary education and 27 percent are college graduates. Given the low proportion of those with higher education degrees, the probability of finding regular employment or seeking self-employment falls by 0.08 points in the SC community. Borooah, Dubey, and Iyer (2007) also 
observe that the chances of being employed in salaried jobs for recent graduates among the socially marginalized are 0.05 points higher than the average illiterate prime-aged population. Additionally, 38.7 percent of upper-caste Hindu men are employed in salaried jobs, whereas only 19.3 percent prime-aged SC men are employed in the same sector (Borooah, Dubey and Iyer 2007).

\section{THE PARADOX BETWEEN SOCIAL AND ECONOMIC DISADVANTAGES}

Political reservation has a determining effect on education and child labor in India. It is difficult to assess the impact of political reservations in the educational sphere because often, reservations benefit specific individuals who are already in an advantageous position within the SC and ST groups. As Pande (2003) suggests, the SC population experiences more job opportunities due to elite capture, as more well-off individuals within the SC caste group benefit more from the policies than those who are not as socio-economically privileged in another caste group. Reservations based solely on caste identity extend the benefits to even those who may not require it based on socio-economic gounds, i.e., a relatively small proportion of marginalized groups who are economically prosperous. Consequently, many economically marginalized caste groups cannot benefit from affirmative action policies effectively.

\section{CHILD LABOR: A CAUSE OF ECONOMIC DEPRIVATION}

In many rural regions in India, laborers from the SC and ST communities are offered a lower wage than their non-marginalized counterparts (Agrawal 2013). In this situation, parents have few options but to send their children to work in order to earn enough income to survive. Child labor in the ST community continues to increase even as the government extends welfare funds. As has been noted by researchers (Pande 2003), ST leaders tend to invest more in welfare programs that make public goods like roads, water, and electricity easily available, but in the process, they tend to neglect the need for primary education for children that can lead to employment or self-employment in the future. A probable reason for this is to make basic amenities like roads, electricity and water works available to the community since they often do not benefit from national welfare programs. This is evident in the recent findings noted by Statista (2020), which shows that dropout rates from secondary school among the ST community is 22.3 percent, higher than that of the SCs and the general castes (Appendix, Table 2). On the other hand, the SC reservation scheme prioritizes both government employment and access to primary education (Duflo 2005).

Despite the policies available to the SC community, Kaletski and Prakash's (2016) regression analysis shows that regardless of the promotion of primary education in SC communities, SC households have high child labor rates. Ideally, increasing access to primary education should ideally result in a significant drop in the rates of child labor; however, as the authors suggest, increasing prevalence of child labor can be attributed to the group's integration into mainstream communities. Because district welfare plans for the SC community must now take into account issues that are relevant for everyone living in the region-instead of focusing on narrower issues that are particular to the needs of the SC community-distribution of the benefits from the SC reservation and welfare policies are spread across all other social groups living in the community (Chaudhuri 2015 as cited in Kaletski and Prakash 2016). Additionally, elite capture among the SCs is another possible explanation (Kaletski and Prakash 2016). 
The following analysis attempts to explain why marginalized communities have lower rates of education and employment despite affirmative action policies.

\section{ANALYSIS}

Persistent poverty and unemployment, particularly among those belonging to the lower castes, result from many factors. To start with, data on Indian demographics is incomplete, which means the existing data are easily manipulated to mislead political action. With the proliferation of potentially biased data, many political leaders and caste subgroups can influence policies, keeping some of the most disadvantaged groups away from quality education and fair employment opportunities through the practice of political cronyism.

The current system of political reservation relies on demographic data from the national census. Though the composition of the population in urban political constituencies changes frequently due to urban transition, updated census data is only available every ten years. This means that reservation policies for the socially marginalized, especially the number of seats reserved for them in local governments, are rarely based on the most current demographic trends or up-to-date data. Further, migration and new settlements change the numerical and caste composition of voting bodies in an area. The number of seats held for marginalized groups has to be proportional to their population in the states; thus, a change in the population also contributes to a change in seats held for the population (Chin and Prakash 2011). Given the ever-changing nature of data and the lack of updated information, some states may have incorrect representation, significantly affecting the division of benefits in these states.

Inaccurate data and representation result in a flawed selection of policies for the marginalized, especially in communities where SCs cohabitate with other castes. These policies are formulated by elected individuals who must consider the entire population inhabiting the region; this allows for the general caste communities in the region to reap the benefits from policies meant to serve more disadvantaged SC communities. By allowing all castes to benefit from greater SC representation, the SC community will need even more targeted policies to address their particular needs which are often left unaddressed. Because these leaders prove to be more fruitful for the general caste community and add to their existing benefits, having SC leaders then becomes a positive externality for the already advantaged general caste population in that area. Since the SC community cannot always benefit from policies that are primarily intended to cater to their needs (Kaletski and Prakash 2016), they do not have an incentive to further communicate their needs to government leaders. Additionally, given the group's history of socio-economic discrimination based on their position in the social hierarchy, the SCs are often unable to effectively exert their demands.

Coincidently, where cohabitation serves as a positive externality for general castes, living with other general caste communities becomes a negative externality for the SC community. By trying to cater to everyone's demands in an urban area, policies tend to have a more general perspective instead of a targeted perspective, and eventually, SC leaders are often unable to address their communities' most pressing needs. The SC community not only cohabitates with other general caste communities but also with other Scheduled subcastes, of which there is a varying 
degree of economic advantage, leading to fragmentation among caste groups. The effects of SC cohabitation are evident in employment and higher education policy reservations.

Since SC families typically have to send their children to work at an early age to help increase their family's income, children are deprived of sufficient education to obtain jobs, despite reservation policies; this levies a direct cost on their people. Additionally, inadequate information can often lead to overproduction in the economy (Nechyba 2015). As more jobs are created for the SC community, the market overproduces laborers, some of whom are children trying to contribute to their family's subsistence. Relatively more children from the ST community go to school, resulting in lower rates of child labor in the ST group. This difference stems from their isolation from the mainland; without cohabitation with general castes, ST leaders in rural areas have the liberty to formulate policies that cater to their own specific needs. As noted by Kalestki, Prakash, and Prakash (2016), "a one percentage point increase in seats reserved for STs in the state legislative assembly leads to .094 decrease in the total number of children working in a given household...a one percentage point increase in seats reserved for SCs leads to a .014 increase in the total number of children working (though not statistically significant)" (65).

Certain members of the more affluent SC sub-castes may only need affirmative action in the employment sector. While advocating and investing in employment programs makes the community believe that they now have better choices in terms of jobs and employment, it pushes them away from advocating for other possible choices that may make their future even more lucrative. Here, Libertarian Paternalism, or the act of influencing public behavior and choices while leading people to believe that they have the freedom to make individual choices, plays a determining role. Libertarian Paternalism tries to "nudge people in certain directions without eliminating freedom of choice" (Nechyba 2015, 1142). However, when leaders develop policies like job reservations, they push individuals and funds away from other sectors that need improvement - especially education. Underestimating the value of education, SC and ST families unknowingly enable the decrease in funding for improved school systems by agreeing to the policies suggested by the leaders. To bring in income for short-term survival, many members of the minority community inadvertently lose the opportunity for a bright future. This shows that when affirmative action focuses on the reservation of jobs rather than providing basic education, adverse effects can manifest in the form of declining educational levels and a growing market for children and other forms of unorganized labor.

Overall increased rates of employment help political leaders maintain their positions. By decreasing unemployment rates and increasing GDP, leaders and their policy decisions are deemed successful because they contribute both to the state's and the nation's welfare. Politicians and policymakers may continue to press for further employment improvement, but they may not care as much about educational reforms for the SC community because it does not provide a short-term, direct reflection on them as a leader.

Furthermore, certain beneficiaries also misuse their socio-economic power to benefit from reservation policies. This can also be seen as a form of "rent-seeking". Many affluent upper-caste Hindus utilize their social power to use benefits reserved for the minorities. For example, one way they do so is by producing false documents. These tactics result in less reserved seats in the job and higher education market that should be reserved for the economically-disadvantaged. As 
others take up reserved spots, many from the ST and SC communities struggle to find employment or obtain higher education, further contributing to unemployment and poverty in society. Additionally, in a similar process to that described above regarding child labor, the market struggles to create more jobs to meet the rising demand as more SC and ST people are out of formal work. The lack of formal jobs to meet labor demands creates an informal labor market where workers have to engage in menial labor jobs that pay below the minimum wage.

Thus, misleading data, inadequate policies, and corrupt practices of elites and politicians prevent the reservation policy from being effectual, and contribute further to the poverty and discrimination experienced by the socially underprivileged. The affirmative policy fails to produce benefits for the intended population and hampers the nation's overall development. The following section provides recommendations that may help the Indian government realize the full potential of SC and ST representation.

\section{POLICY IMPLICATIONS AND RECOMMENDATIONS}

The Scheduled Castes and Scheduled Tribes continue to suffer from social exclusion and poverty in India despite continued efforts and reservation policies. Corrective methods and improved reservation policies can reverse these trends. Below, the section summarizes key issues with the policy and highlights some recommendations for improving the policy, such as reliable data use and geographically widespread implementation of reform.

First, gathering reliable data is a significant aspect in correcting India's reservation policy. The population composition and demographics change frequently, so relying entirely on census data only collected every ten years is not wise. The central government must conduct full census surveys more frequently or conduct smaller census-like surveys to update the relevant data needed to understand the pressing needs of the minority communities.

Second, the false declaration of caste identity using false documents takes away benefits from the intended candidates. To prevent this, the government should introduce strict screening methods to check the validity of identifying documents to prevent inconsistent information. Setting up a screening method may result in additional upfront costs for the government but it will prevent the long-term higher costs associated with erroneous allocation of resources.

Furthermore, policymakers should invest in studying the resources that different caste groups in particular regions demand, especially those where different marginalized sub-castes or multiple caste groups cohabitate. These measures will enable the formulation of precise policies designed to tackle place-specific issues to address needs of the different caste groups, ensuring the region's overall development. In areas where sub-castes live together, the local district government should address the needs of the most underprivileged first, paving the way for holistic development. For example, since the ST community lives in isolation, policymakers should try and provide them with the educational or employment facilities they have not received due to geographical barriers.

Third, the government should introduce targeted reforms in the educational structure that ensures that localities where socio-economically underprivileged communities reside have more 
schools equipped with better faculty and technological resources. There is a stark difference in the overall educational standards between forward caste Hindus and the SC and ST community (Borooah, Dubey, Iyer 2007). With better education, individuals will be able to take up more skilled jobs, thus removing negative societal externalities like child labor and unorganized labor markets. In the current policy structure, the lack of focus on primary and secondary schools makes reservation in higher educational institutes (e.g., management, engineering, and medical schools) and in government jobs little more than a cosmetic exercise. Moreover, since educational reservations are only available in higher educational institutions, they are confined to urban areas and disproportionately assist members belonging to caste groups who are the least in need of help (Borooah, Dubey, Iyer 2007). Improving the quality of basic education will also help reduce child labor as parents will feel encouraged to send their children to school.

Lastly, employment and educational reservation should be extended based on financial grounds rather than caste grounds to ensure all those in need are able to benefit. The sophisticated screening methods described above will ensure that benefits are being extended to the right people, providing a more effective way to battle elite capture seen in the current caste-based reservation system.

All the necessary amendments to the current reservation policy are possible if the government takes adequate measures to update its data by eradicating inconsistent information and introducing necessary reforms in different states. Fair implementation of existing reservation policies will ensure that the targeted community is being served and help reduce administrative costs that the government may otherwise have to bear while formulating and implementing reservation policies to provide for those underserved people who are being left out.

\section{CONCLUSION}

India has a growing population of which the Scheduled Castes and the Scheduled Tribes are an integral part. Due to continued cultural, political, and socio-economic discrimination, these caste groups have had unequal opportunities in every sphere of life, resulting in high poverty and unemployment rates. While the government has introduced affirmative policies to counter these challenges, its success can only be optimized when these policies stand on authentic information.

As discussed above, the STs are the most impoverished community in India (Yadavar 2018), making up 9 percent (Statista 2020) of India's population and living in the poorest wealth quintile with no access to health or welfare programs due to geographical isolation and economic insufficiency. According to the National Herald (Divakar 2018), 43 percent of Scheduled Tribes and 29 percent of Scheduled Castes are below the poverty line. Many individuals belonging to the SC and ST groups are socio-economically privileged and powerful, despite these groups being underprivileged as a whole. While some have genuinely benefitted from the reservation policy to acquire their heightened social status, others have used unfair means. To ensure that the reservation policy serves the purpose for which it was designed, the Indian reservation policy needs to primarily focus on the economic needs of these different social groups and avoid depending on caste as the sole criteria for welfare benefits. 
Reducing misinformation in society is of critical importance and would better ensure the success of the current Indian reservation policy. It is also essential for national government officials to provide oversight so that local administrators distribute welfare benefits to alleviate social ills rather than promote personal political agendas. With necessary checks in place, high administrative costs, deadweight loss in the economy, and negative externalities resulting from unorganized labor markets and unemployment can be avoided. Addressing these problems will ensure a brighter future for SCs and STs and restore equal opportunities for all under the Indian reservation policy. 


\section{APPENDIX}

Table 1.

\begin{tabular}{|l|l|}
\hline & Share of population \\
\hline General caste Hindus & $30 \%$ \\
\hline Scheduled Castes & $20 \%$ \\
\hline Scheduled Tribes & $9 \%$ \\
\hline
\end{tabular}

Source: Author visualization of Statista 2020

Table 2.

\begin{tabular}{|l|l|}
\hline & $\begin{array}{l}\text { Percent of population that dropped out of } \\
\text { secondary school }\end{array}$ \\
\hline National Average & $17.06 \%$ \\
\hline Scheduled Castes & $21.8 \%$ \\
\hline Scheduled Tribes & $22.3 \%$ \\
\hline
\end{tabular}

Source:Author visualization of Jebaraj 2020, Statista 2020 


\section{REFERENCES}

Agrawal, Tushar. 2014. "Gender and caste based wage discrimination in India: some recent evidence." J Labour Market Res., (47): 329-340. Accessed March 23, 2021.

https://labourmarketresearch.springeropen.com/track/pdf/10.1007/s12651-013-0152-z.pdf

Anderson, Robert. 2011. "Social Stratification.” Oxford Bibliographies, September 9, 2014. Accessed March 23, 2021. https://www.oxfordbibliographies.com/view/document/obo9780199756384/obo-9780199756384-0053.xml

Borooah, Vani K, Amaresh Dubey, and Sriya Iyer. 2007. "The Effectiveness of Jobs Reservation: Caste, Religion and Economic Status in India." Development and Change, 38 (3): 423-445. Accessed May 9 ${ }^{\text {th }}, 2020$ http://www.econ.cam.ac.uk/peoplefiles/faculty/si105/Jobs\%20ReservationDAC.pdf

Chin, Aimee, and Nishith Prakash. 2011. "The redistributive effects of political reservation for minorities: Evidence from India." Journal of Development Economics, 96: 265-277 Accessed May $9^{\text {th }}, 2020$ https://www.sciencedirect.com/science/article/abs/pii/S030438781000115X

Divakar, Paul. 2018. "India not free 71 years on, rising inequality, unemployment to blame." National Herald. August 10, 2018. Accessed January 17 $7^{\text {th }}, 2021$ https://www.nationalheraldindia.com/opinion/india-not-free-71-years-on-rising-incomeinequality-to-blame

Duflo, Esther. 2005. “Why Political Reservations?” Journal of The European Economic Association, 3 (2-3): 668-678 Accessed May $9^{\text {th }}, 2020$ https://onlinelibrary.wiley.com/doi/epdf/10.1162/jeea.2005.3.2-3.668

George, Alex Andrews. 2020. "Reservation in India - Explained in Layman's Terms.” Clear $I A S$. Accessed May $9^{\text {th }}, 2020$ https://www.clearias.com/reservation-in-india/

Jebaraj, Priscilla. 2020. "Fall in percentage of school education funds for SC, STs" The Hindu. Accessed November $28^{\text {th }}, 2020$. https://www.thehindu.com/education/fall-in-percentageof-school-education-funds-for-sc-sts/article31026183.ece

Kaletski, Elizabeth, and Nishith Prakash. 2016. "Does Political Reservation for Minorities Affect Child Labor? Evidence from India." World development, 87: 50-69 Accessed May $9^{\text {th }}, 2020$ https://www.sciencedirect.com/science/article/abs/pii/S0305750X16303989

Ministry of Social Justice and Empowerment. 2021. "State-Wise Percentage of Population Below Poverty Line by Social Groups, 2004-05.” Government of India. 
Accessed January 19, 2021

http://socialjustice.nic.n/UserView/index?mid=76672

Nechyba, Thomas J. 2017. "Externalities in Competitive Markets.” In Microeconomics: An Intuitive Approach. 744- 776. Boston: Cengage Learning. https://1lib.us/book/5951536/447e10

Nechyba, Thomas J. 2017. "Public Goods.” In Microeconomics: An Intuitive Approach. 10401077. Boston: Cengage Learning. https://1lib.us/book/5951536/447e10

Nechyba, Thomas J. 2017. "Governments and Politics." In Microeconomics: An Intuitive Approach. 1094- 1117. Boston: Cengage Learning. https://1lib.us/book/5951536/447e10

Pande, Rohini. 2003. "Can Mandated Political Representation Increase Policy Influence for Disadvantaged Minorities? Theory and Evidence from India." The American Economic Review, 93(4): 1132-1151. Accessed March 23, 2021 https://www-jstororg.proxygw.wrlc.org/stable/pdf/3132282.pdf?refreqid=excelsior\%3A3b60b4872f195e52 e8a9bb66bba7f312

Statista. 2020. "Rate of average annual dropout across schools in India in academic year 2016, by level." Statistical Research Department. October 16, 2020 Accessed November $28^{\text {th }}, 2020$.https://www.statista.com/statistics/661218/averageannual-drop-outs-in-schools-india/

Statista. 2020. "Share of Indian population in 2019, based on caste." Statistical Research Department. October 16, 2020. Accessed January $17^{\text {th }}, 2021$. https://www.statista.com/statistics/1001016/india-population-share-by-caste/

Taiwo, Olufemi O. 2020. "Identity Politics and Elite Capture." Boston Review, May 7, 2020. Accessed October $17^{\text {th }}, 2020$. http://bostonreview.net/race/olufemi-o-taiwo-identitypolitics-and-elite-capture

Yadavar, Swagata. 2018. “Scheduled Tribes Are India’s Poorest People.” India Spend. Accessed May $9^{\text {th }}, 2020$ .https://www.indiaspend.com/scheduled-tribes-are-indias-poorest-people-18413/ 